\title{
Team monitoring useful or not useful?
}

\author{
Beenish Arshad ${ }^{1 *}$, Muhammad Ali ${ }^{2}$, Amna Niazi $^{3}$ \\ ${ }^{1,2}$ FAST School of Management, National University of Computer and Emerging Sciences, Lahore, Pakistan \\ ${ }^{3}$ Institute of Business and Management, University of Engineering and Technology, Lahore, Pakistan
}

\section{Keywords \\ Trust \\ Team effectiveness \\ Interdependence \\ Monitoring \\ Team effort}

Received: 6 March 2020

Accepted: 18 May 2020

Published: 12 August 2020

\begin{abstract}
The present study investigates the mediating role of team monitoring in intra-team trust and team effort relationships. Intra-team trust influences coordination between team members, while team monitoring is a process to assess and evaluate team processes and performance. This research analyzes whether team monitoring influences the trust-effort relationship in ongoing teams of organizations in Pakistan. A field survey approach was used to test the research hypothesis. Data were collected from a sample of 100 team members and supervisors of 20 ongoing teams in organizations of different sectors. In order to explain the association between variables, the model was tested using Structural Equation Modeling (SEM) using AMOS. The findings showed that hypothesized model fit reasonably well based on comparison fit indices. The results show that team monitoring significantly influences the relationship between intra-team trust and team effort for teams operational in chosen organizations. The study adds valuable insights to the existing literature on team dynamics by analyzing the aforementioned relationships in the South Asian organizational context.
\end{abstract}

\section{INTRODUCTION}

Organizations are defined as social units or human grouping deliberately established for the accomplishment of specific objectives (Etzioni et al., 1964). All organizations have a management structure that determines relationships between different activities and members, subdivides, assigns roles, responsibility and authority to carry out different tasks (Drucker, 1992). They obtain inputs from environment; respond to demands of stakeholders and offer products and services accordingly. There are certain pressures on every organization in order to respond to environmental demands and constraints and also to exploit opportunities (Damanpour \& Schneider, 2006). The changing environment dynamics requires organization to be more team oriented (Lawler, 1995). As complexities increase in the external and internal environment, individual working becomes less efficient. Moreover, some situations require creativity and diverse skills, experiences and judgments to achieve better results (Conti \& Kleiner, 1997). Teamwork is becoming more important because effective implementation of work teams in organizations can enhance work motivation and increase job satisfaction (Griffin, Patterson, \& West, 2001). Teams have become indispensible for progressive organizations as they play role in problem solving and future progress in organizations.

Teams are defined as a group of people formed in order to achieve organizational goals (Beaubien \& Baker, 2004). These teams are formed to achieve certain well defined objectives along with producing goods and services (Barrick et al., 2012). The primary purpose of a team is to achieve efficiency and effectiveness. Teams also improve work and individual effectiveness within an organization (De Meuse \& Liebowitz, 1981; Rijal, 2016; Woodman \& Sherwood, 1980). The ability to meet new demands of innovation is closely related to development of teams within the organizations (Gann \& Salter, 2000). Team work is interdisciplinary in nature and cooperation between the team members is necessary. Teamwork may be sustained by commitment to shared set of knowledge, skills and abilities rather than permanent tasks carried on a day to day basis (Morey et al.,

\footnotetext{
*corresponding author: Beenish Arshad

†email: beenish.arshad@nu.edu.pk
} 
2002). Such teams exist to perform relevant tasks and exhibit task interdependencies in terms of goals, workflow and knowledge. They are embedded in organizational context that sets boundaries, constrains the team and influences exchanges with external units (Denison, Hart, \& Kahn, 1996; S. Kozlowski \& Bell, 2003).

There are different types and sizes of work teams in organizations. Some teams are temporary and disband after achieving the desired goals. Others are ongoing and are permanently associated with the organization. Functional or work teams are ongoing teams organized around defined interdependent functions and are characterized by recurring activities (Putnam, 1992). These teams are formally defined and members have shared goals related to development of products and services. They provide resource allocation and overall direction to the organization members (Cohen \& Bailey, 1997). Temporary teams are formed for limited time and for specialized tasks (Stone, Kaminka, Kraus, Rosenschein, et al., 2010). Researchers have characterized teams into various general typologies as effort to distinguish broad range of teams (S. Kozlowski \& Bell, 2003). Sundstrom, McIntyre, Halfhill, and Richards (2000) integrated the Sundstrom, De Meuse, and Futrell (1990) and Cohen and Bailey (1997) typologies to yield six team categories: production, management, service, project, action and advisory. Ongoing teams include production, service and management teams. Production teams include core employees who produce products and services. Service teams engage in ongoing transactions with customers to cater their needs. Management teams are composed of business units with responsibility of directing and coordinating lower level work units. Project teams are temporary teams such as product development teams. These perform specialized and time limited tasks. Action and performing teams are also temporary in nature and are composed of experts who engage in complex performance events (S. Kozlowski \& Bell, 2003).

There are a number of factors that affect team effort within ongoing teams. Some factors include individual competencies of team members; skills, processes, tools and techniques; interpersonal skills, communication and personalities of team members; core values of team; shared vision, purpose, goals; and organizational values. Intra team processes include interactions that take place among team member (Campion, Medsker, \& Higgs, 1993). Intra team trust is considered to be an important influence on coordination between individuals and several benefits for individuals and organizations are associated with trust. Trust may affect the relationship between group process and team performance (Dirks, 1999).

Members interact frequently in teams, share information and coordinate efforts towards accomplishment of goals. Individuals become committed to team goals when they perceive a sense of identification with their teams. Collective responsibility is a condition when success of group effort is distributed across all members rather than an individual (Scardamalia et al., 2002). Along with individual capabilities, commitment on part of each team member to do the work is necessary to make team effort succeed (Scardamalia et al., 2002). Team identification is developed through sense of membership with a team which is emotionally significant aspect of one's identity. Thus, they become committed to team and its goals rather than individual motives hence exert significant effort resulting in high team performance (Van Der Vegt \& Bunderson, 2005). Thus collective team effort also plays an important role in.

Another factor which has an impact on team processes is team monitoring. At team level monitoring is defined as observing activities and performance of team members (Dickinson \& McIntyre, 1997; Wartika, Surendro, Satramihardja, \& Supriana, 2015). Monitoring should enable teams to get an idea of the mistakes made by team members and analyze the pace and rythym of team activities (Bell \& Kozlowski, 2002). Research has found that team monitoring benefits the overall team effectiveness by enhancing co-ordination and encouraging feedback (Bell \& Kozlowski, 2002).

This study aims to discover if there is any interplay between intra team trust and team effort in ongoing teams of Pakistan. Apart from intra team trust, team monitoring will be studied as mediating variable between intra team trust and team effort. This research will be beneficial for organizations where work is done in teams. They can regard the importance of developing team trust in work teams. Organizations can also develop methods to improve team effort and find out better ways of team monitoring to improve work performance.

\section{LITERATURE REVIEW}

Salas, Dickinson, Converse, and Tannenbaum (1992) defined team as two or more individuals who have specific roles, perform interdependent tasks and share common goals. Organizations are operating in a dynamic and competitive environment (Baker, Day, \& Salas, 2006). Factors such as increased competition, consolidation and trend of continuous innovation all over the world create pressure on organizations to cope up with environmental challenges. Given the environment, teamwork is very much needed 
for organizations to operate, interact and achieve organizational goals (Baker et al., 2006). Team work leads to better products and services and fewer errors in routine tasks. Members of a team need specific Knowledge, Skills and Abilities (KSAs) to work effectively (Cannon-Bowers, Tannenbaum, Salas, \& Volpe, 1995). There are a number of benefits of sharing knowledge and skills between team members as skill diversity leads to positive outcomes (Way, Chou, \& King, 2000). Teams are formed in order to achieve organizational goals by combining group of people with specific knowledge, skills and abilities. In present organizational structures, work is designed around autonomous or semi autonomous teams (Angriani, Ariffin, \& Rahmawati, 2017; Cascio, 1995; Hackman, 1990; Manz \& Sims, 1995). Teamwork facilitates diverse and creative solutions to challenging problems in an organization (Hall, 2005). Individual team members are assigned specific roles; they identify and analyze problems, define goals and assume joint responsibility for the goals (Hall, 2005). Research has been conducted to analyze benefits of teamwork in different industries (Manser, 2009). The processes involved in providing products and services to the customers are interdisciplinary and require personnel to work in teams. It has been recognized that working in multidisciplinary teams and expending high team effort is crucial in providing quality products and services to customers (Baker et al., 2006). According to Robbins (2001), there are four common types of teams working in an organization; problem solving teams, cross functional teams, self managed team and virtual teams. Problem solving teams comprise of individuals usually from the same department who work together to improve quality, efficiency and make recommendations remove any deficiencies in the current structures. Cross functional teams consist of employees from different departments who work together to accomplish a task. Self managed teams are comprised of individuals who perform interdependent tasks and also assume responsibilities of supervisors. These tasks include planning and scheduling of work, assigning tasks, making decisions and solving problems. Virtual teams use technology to combine members dispersed physically in order to accomplish specific objectives.

Several studies have been conducted in organizational settings but still most of the researchers have not revealed information about the prevalence, functions and characteristics of work groups in organizations especially ongoing teams (Devine, Clayton, Philips, Dunford, \& Melner, 1999). Moreover, less research has been conducted on team work particularly in South Asian perspective. One important con- sideration in understanding teams is that teams cannot be understood without taking into account their context, and the knowledge we deduce about team in particular setting cannot be generalized to another team in a completely different setting (Hackman, 1990; McGrath, 1991). Types of teams vary in context of the time duration for which they have been formed. It is very important for organizations to distinguish between short-term; ad hoc teams that are formed for one particular task cycle opposed to long-term ongoing teams. Ongoing teams are those that are continually assigned new tasks or do the same work tasks in cyclical fashion (Devine et al., 1999). Ongoing teams are formally defined by an organization and are engaged into ongoing and recurring activities (Putnam, 1992). On the other hand temporary or ad hoc teams are formed for a specific project or achieving a specific objective. They disperse after successful accomplishment of desired goals (Stone et al., 2010). Ongoing project teams are teams with relatively stable membership that interact with clients or customers, solve problems, devise plans or participate in decision making. They perform similar tasks as ad hoc teams but on a continuous basis (Devine et al., 1999). Researchers have shown that the major difference amongst ongoing and ad hoc teams is the time duration in which they are intact and duration of tasks they perform (Barrick et al., 2012).

Intra-team processes are the interactions that take place among the members of a team (Hackman, 1990). Team processes are the means by which the individuals working in a team setting work interdependently in order to utilize resources, their skills and expertise (Marks, Mathieu, \& Zaccaro, 2001). Intra-team trust can lead to cooperative behavior amongst individual members and hence increased team effort (McAllister, 1995). Some organizations are increasing co-operation amongst team members by re-engineering their structures into flatter team based forms in which members of teams are empowered and authority is decentralized.

Trust is viewed as an expression of one party having confidence on another party in an exchange; and that they will not be harmed or put at risk by the other party (Axelrod \& Hamilton, 1981; Zucker, 1987). Some scholars define trust as the degree to which one party is willing to rely on another in a given situation with a sense of relative security even when negative consequences are possible (Jøsang \& Presti, 2004). Trust is a complex and multi-level construct in theory. Some scholars have worked on getting comprehensive view of trust by gathering information from other disciplines. They have worked on different characteristics in different levels of trust such as individual, group and or- 
ganizations. Moreover, organizational change also has an impact on trust level amongst the employees (Rousseau, Sitkin, Burt, \& Camerer, 1998).

There are various theories linked to the concept of trust. According to Social exchange theory, social cues and behaviors can help build trust in future rewards by showing commitment and trustworthiness to social exchange (Luo, 2002). Fukuyama (1996) explained importance of interpersonal trust in sociological perspective. Classical researchers have also explained that economic prosperity can be achieved through mutual trust in members of economy as social transactions require trust between the members involved. Trust is complex multidimensional construct which encompasses emotional, cognitive and moral elements (Barber, 1983). Intra-team trust determines expected behavior of team members which is the outcome of individual team member's values, attitudes and emotions (Jones \& George, 1998). When work is done in self managed teams, interpersonal trust and co-operation leads to organization effectiveness because members have more autonomy (Dunphy \& Bryant, 1996). Scholars have acknowledged that intra-team trust leads to co-operation and thus improves team effort and performance (Axelrod \& Hamilton, 1981; McAllister, 1995). Many researchers have examined intra-team trust as an important variable contributing towards high team performance as well as work group processes. Past research studies have also shown a positive relation between trust and performance in ongoing teams (Costa, 2003; Rispens, Greer, \& Jehn, 2007). When there is high level of trust within a team, it results in high level of motivation and coordination in work group processes which results in improved team effort. This proposition has been the main idea of prior researches in organizational behavior (Dirks, 1999). However, it is argued that such proposition rather appears to be appealing but there is not much evidence to prove its validation .Moreover, Dirks (1999) studied that although trust is an assurance for an effective group but it is not necessary that the effect of trust has to be direct, for example, interpersonal trust can indirectly affect group effort. Teamwork includes team processes which include interactions and effort towards accomplishment of team goals. Team members work in an interdependent manner that converts inputs to outputs through behavioral, cognitive and verbal activities that are directed towards organizing tasks to work towards accomplishing goals (Marks et al., 2001). Team effort can be considered to be interactions with tools, machines and systems to achieve goals (Cannon-Bowers \& Salas, 1997). Individual factors such as personality and goal orientation have an impact on indi- vidual intentions that influence team processes (Phillips \& Gully, 1997; VandeWalle, Brown, Cron, \& Slocum Jr, 1999). Once the intentions are formed, they influence performance by increasing the expended effort towards goal attainment (Austin \& Vancouver, 1996; Bandura, 1997). The process of transforming effort into team performance evolves over time. Intentions are formed which are translated into goal directed effort. Then the team members receive feedback on the effectiveness of the effort they expend and then increase or decrease team effort based on the results of the feedback (Carver \& Scheier, 2001). If team members perceive that high performance is beneficial to them only then they will be motivated to exert effort and perform well on the job (Van Knippenberg, 2000).

As teams exert effort to accomplish tasks and goals, their activities may be monitored in order to oversee whether work is done efficiently and effectively. Scholars define team monitoring as a function to observe the activities and performance of team members (Dickinson \& McIntyre, 1997). Team monitoring is mutual performance monitoring which allows team members to assess and evaluate how they are performing (Damanpour \& Schneider, 2006). They ensure that work procedures are followed accurately (McIntyre \& Salas, 1995). Teams which are monitored routinely should be able to obtain awareness regarding timing and pace of team members and how well they are performing (S. W. Kozlowski, 1998). Monitoring enables team members to be aware about their mistakes and deficiencies which they can correct in order to enhance team effort. Monitoring is important for team effectiveness as it improves coordination and encourages feedback. Team monitoring improves team effort and performance because team members can attain information about other team members and improve synchronization of their activities and minimize detrimental behaviors by assisting other team members (Marks et al., 2001). Team monitoring is considered crucial for effective teamwork (LePine, Piccolo, Jackson, Mathieu, \& Saul, 2008). Moreover, team monitoring can be considered as a mechanism of implicit coordination and allows members to anticipate needs and future actions of other team members. They can use the information from team monitoring procedures to adjust own behavior and thus improve overall performance (Kolbe et al., 2014). Team members may identify their own mistakes and mistakes in other member's actions as well as their behaviors and then react for necessary improvements (Salas, Sims, \& Burke, 2005). According to high performing teams demonstrated better behaviors immediately after team monitoring such as providing assistance to other team members. Thus it can be implied that team mon- 
itoring can lead to improvement in team effort (Burtscher \& Manser, 2012).

This research is conducted in the South Asian perspective and the country studied is Pakistan. Cultural dimensions play an important role in determining organizational practices. Pakistan's culture fits into the collectivism dimension. This research study will thereby analyze whether the collectivistic culture dimension plays a role in high performance of teams as teamwork itself is a collectivistic phenomenon.

\section{Intra Team Trust and Team Effort}

Intra-team trust has a positive relationship with effort because team members are motivated to work hard towards goal accomplishment (De Jong \& Elfring, 2010). According to theories of collective work motivation, effort is motivated by social considerations (Kidwell Jr \& Bennett, 1993). This is particularly the case in ongoing teams where interpersonal ties and norms have become strong over time (Saunders \& Ahuja, 2006). Trust promotes team effort particularly in ongoing teams because social norms and affective considerations motivate team members to work hard (Ferrin, Bligh, \& Kohles, 2008). Team effort also increases when team trust is increased over the time when team becomes mature. This is because relationships become stronger and team members identify with a particular team (Lewicki, Bunker, et al., 1996). Team trust promotes team members to work hard and persistently thus producing a high output. Studies have supported the evidence that there is a positive relationship between team trust and team effort (Liden, Wayne, Jaworski, \& Bennett, 2004). Therefore, performance benefits through intra-team trust are brought through team effort as the following.

H1: There is a positive relationship between intra team trust and team effort.

\section{Mediating Role of Team Monitoring}

According to research, it can be proposed that benefits from intra-team trust can be increased through team monitoring (De Jong \& Elfring, 2010). Research conducted on trust-monitoring relationship by McAllister (1995) suggest that the impact of trust on monitoring depends on the type of trust and monitoring under consideration. Some types of team monitoring involve deliberate control over team members while other kinds of team monitoring allow assisting other team members. Monitoring which allows assisting team members is enhanced by high levels of intra-team trust and therefore improves team performance. Monitoring done in teams with high levels of intra-team trust enhances* effort and performance by reducing process losses that hinder teams to reach high levels of productivity (Langfred, 2004). Monitoring also reduces motivational losses by reducing social loafing in a team. Coordination is also improved through team monitoring which increases productivity. Prior research supports the evidence that team monitoring has positive impact on effort expended in a team setting (Marks et al., 2001; McAllister, 1995). The following hypothesis can be proposed:

H2: Team monitoring partially mediates the relationship between intra-team trust and team effort.

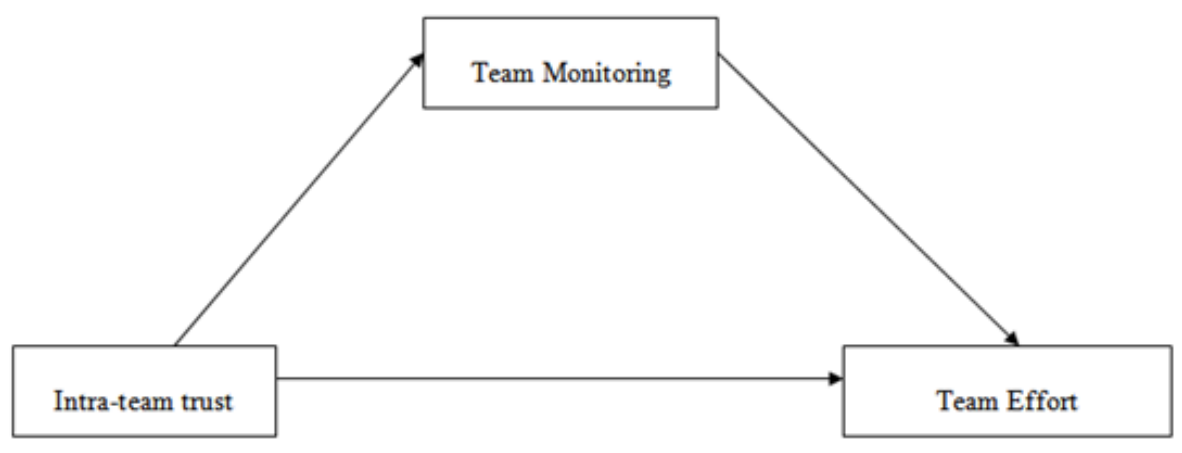

FIGURE 1. Theoretical framework

\section{RESEARCH METHODOLOGY}

\section{Data Collection and Sampling Procedure}

This research was conducted to analyze the impact of intra team trust on team effort when team monitoring mediates the relationship. Data were collected to analyze the cause and effect relationship between variables. The research design was cross sectional as data were collected from differ- ent organizations at specific point in time. A field survey approach was used in order to test the research hypothesis. Ongoing teams functional in this organization were identified by a meeting with executives working in this organization. The technique used for sampling was probability sampling under which random sampling technique was used. Before distributing the questionnaire, a pilot study was con- 
ducted to evaluate the questionnaire. The pilot study results were used to analyze whether the respondents understood the questionnaire well before actual data collection took place.

Data was collected from team members and supervisors through a self explanatory structured questionnaire. The questionnaire included a cover letter that explained the purpose and importance of this research and that the results would be kept confidential. Data were collected from ongoing teams working in several organizations operating in Lahore, Pakistan. The sample consisted of total 100 team member responses in 20 ongoing teams from different sectors of organizations. The overall response rate was $84 \%$. In order to ensure sufficient representation of the team members for data analysis, a sampling restriction was also set to collect at least 10 responses from each organization. This research study relies on direct responses from ongoing teams' members. Therefore, it can be susceptible to Social Desirability Bias (SDB). In order to minimize SDB, one of the research authors was directly involved in data collection process. The questionnaires for this study were self administered. Previously designed scales for the constructs were adopted which were also empirically tested. Team members were asked questions on team related variables such as intra-team trust, team monitoring, team effort and team performance rather than their personal expectations. This further reduced the personal bias tendencies of the customers. Smart PLS $t$-value test was used in order to test the data for non-response bias. The results indicated no significant differences between respondents and non-respondents with respect to age, gender, tenure, employment status etc.

\section{Demographic Background of Respondents}

A total number of 130 questionnaires were distributed however 100 complete responses were received from team members of ongoing teams. Data was collected from employees of organizations working in teams consisting of 4 to 5 team members. Teams consisted of both male and female respondents aged from 25 to 50 years. The income bracket of the respondents ranged from PKR 30,000 to PKR 60,000. This research study relies on responses from the team members directly. Therefore, it can be susceptible to SDB. In order to minimize SDB, one of the research authors was directly involved in administering the questionnaires. The questionnaires for this study were self administered. Previously designed scales for the constructs were adopted which were also empirically tested. Data was collected from teams working in different organizations and team members were asked about intra team trust and its impact on overall team effort rather than team members' personal expectations. This further reduced the personal bias tendencies of the customers.

\section{Measurement Scales and Data Analysis}

The questionnaire items were adapted from the work of other researchers. A multi item constructs based on five point Likert Scale was used to measure intra-team trust, team monitoring and team effort. The Likert Scale ranged from 1 to $5 ; 1=$ strongly disagree, 2 = disagree, $3=$ neutral, 4 $=$ agree and $5=$ strongly agreed.

The 5 item trust scale used in this study was developed by Hinkin (1998). Originally it consisted of measures regarding trust in peers and team members (Cook \& Wall, 1980; Schippers, 2003). The items in the questionnaire were reduced to just five items that measure intra-team trust. Items which corresponded with the present research were selected. Sample items that measured positive expectations of the team members included "I am confident" and "I am able to count on". In order to check the scale's reliability Cronbach alpha was used. Cronbach alpha greater than 0.70 (Fornell \& Larcker, 1981; Nunnally \& Bernstein, 1994) is considered for the scale to be reliable. The scale's reliability for intra team trust was 0.901 which was acceptable.

The 5 item scale of team monitoring was based on Langfred (2004) and Costa (2003). The scale measures the extent to which team members meet certain goals and obligations. Sample items included: "We watch to make sure everyone in the team meets their deadlines" and "In this team we watch when everyone completes their work on time." The scale's Cronbach alpha was 0.891 which was acceptable.

In order to measure the construct team effort, 5 item scale based on work of (Mulvey \& Klein, 1998) was used. The items measured the persistence of effort of team members. Sample items included "The members of my team work as hard as they can to achieve the team's objectives and "Most members of my team carry their fair share of the overall workload". The scale's reliability was 0.914 which was acceptable. 
TABLE 1. Factor loadings and reliability statistics

\begin{tabular}{llll}
\hline \hline Factors & Items & Factor Loading & Cronbach Alpha \\
\hline Intra Team Trust & ITT1 & 0.82 & \\
& ITT2 & 0.78 & \\
& ITT3 & 0.81 & 0.901 \\
& ITT4 & 0.85 & \\
Team Effort & ITT5 & 0.77 & \\
& TE1 & 0.82 & \\
& TE2 & 0.86 & 0.914 \\
Team Monitoring & TE3 & 0.87 & \\
& TE4 & 0.84 & \\
& TE5 & 0.82 & \\
& TM2 & 0.82 & 0.75 \\
& TM3 & 0.79 & 0.891 \\
& TM4 & 0.75 & \\
\hline \hline
\end{tabular}

\section{Descriptive Analysis of Study Variables}

The following table represents descriptive statistics and Pearson Correlations of the variables studied. Intra team trust was positively correlated with team monitoring $(r=$
0.774, $p<0.01$ ).Team effort is also positively correlated with intra team trust $(r=0.717, p<0.01)$ and with team monitoring $(r=0.727, p<0.01)$.

TABLE 2. Descriptive statistics and correlations between variables (SPSS)

\begin{tabular}{llllll}
\hline \hline & Mean & Standard Deviations & Intra Team Trust (1) & Team Monitoring (2) & Team Effort (3) \\
\hline Intra Team Trust (1) & 9.0600 & 3.62879 & 1 & $0.774^{* *}$ & $0.717^{* *}$ \\
Team Monitoring (2) & 8.7900 & 3.40912 & $0.774^{* *}$ & 1 & $0.727^{* *}$ \\
Team Effort (3) & 8.7600 & 3.89799 & $0.717^{* *}$ & $0.727^{* *}$ & 1 \\
\hline \hline
\end{tabular}

** Correlation is Significant at 0.01 level

\section{RESULTS AND DISCUSSION}

SEM Amos 18 was used to estimate the model. SEM is used to evaluate latent variables with several indicators (Holmbeck, 1997). Using this tool, measurement errors can be controlled when relationships between variables are examined (Baron \& Kenny, 1986; Hoyle \& Smith, 1994). Using confirmatory factor analysis, several indices were measured which included Comparative Fit Index (CFI), chi square statistic divided by degrees of freedom, Root Mean Square Error of Approximation (RMSEA) and Tucker-Lewis Coefficient (TFI). CFI, TLI and GFI, IFI are recommended to be greater than 0.90 while chi square divided by degrees of freedom is recommended to be less than 3 (Bentler \& Bonett, 1980; Bentler, 1990; Hoyle \& Smith, 1994). Some researchers recommend chi square divided by degrees of freedom to be less than 5 (Marsh \& Hocevar, 1985). RMSEA is suggested to be between 0.05 and 0.08 (Browne \& Cudeck, 1993).

The construct validity for the measures in this study was as- sessed by discriminant and convergent validity tests. The validity of the model was tested by using Confirmatory Factor Analysis (CFA). The baseline model including all variables was examined. The baseline model fitted reasonably well with the data. The results of the CFA were $\chi^{2}=203.163$ $d f=85$ CFI 0.901, TLI 0.877, IFI 0.902,. In addition, RMSEA was estimated to be 0.08 . Factor loadings were also significant indicating convergent validity ranging from 0.75 to 0.87 .

The composite reliability values were calculated and were found to be greater than 0.6 therefore indicating convergent validity. Moreover the AVE values were found to be greater than 0.5 indicating convergent validity. In order to test the discriminant validity, the square root of AVE values was found to be greater than the correlation between the variables. Hence the discriminant validity for the constructs was proved. The results are summarized in the following table. 
TABLE 3. Descriptive statistics

\begin{tabular}{llllllll}
\hline \hline & CR & AVE & MSV & MaxR (H) & Intra Team Trust & Team Monitoring & Team Effort \\
\hline Intra team trust & 0.9267 & 0.7168 & 0.726 & 0.947 & 0.8466 & & \\
Team Monitoring & 0.9202 & 0.6978 & 0.726 & 0.894 & 0.7774 & 0.8353 & 0.776 \\
TE & 0.9358 & 0.7448 & 0.654 & 0.968 & 0.7211 & 0.7384 & \\
\hline \hline
\end{tabular}

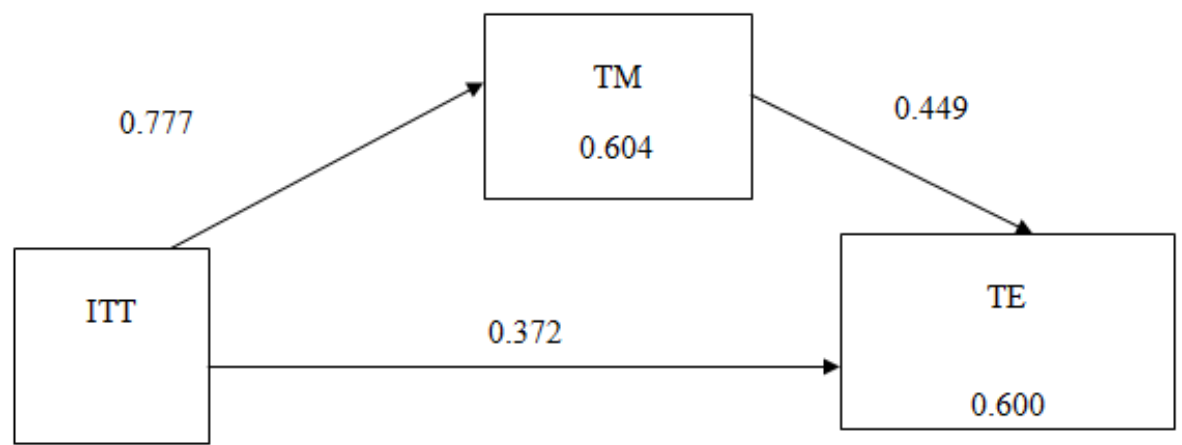

FIGURE 2. Results of the proposed research Model

The present study provides significant results for teams operational in chosen organizations for this study. The aim of this study is to study the impact of intra team trust on team effort when team monitoring mediates the relationship. The mediating role of team monitoring is significant in this relationship since it adds to previous literature of intra team trust and team effort. Intra team trust is an important phenomenon that is important for greater team effort for teams functional in organizations.

Team Monitoring Team Effort 0.724** 0.5290 .0000 According to this study there is a positive relationship between intra team trust and team effort. The results of this study are consistent with the results of the research conducted in the past (De Jong \& Elfring, 2010; Saunders \& Ahuja, 2006; Liden et al., 2004). The mediating role of team monitoring is also significant in this study as it also adds to the previous literature of intra team trust in which it is proved that team monitoring plays an integral role in greater team effort (De Jong \& Elfring, 2010; Marks et al., 2001; McAllister, 1995). Therefore the results from this study imply that team effort is greater for organizations in which intra team trust is prevalent. The results drawn from SEM support the proposed hypothesis and hence prove that team effort is affected by intra team trust when team monitoring mediates the relationship.

TABLE 4. Hypothesis testing

\begin{tabular}{llll}
\hline \hline Hypothesis & $\boldsymbol{R}$ & $R^{2}$ & Sig (2-Tailed) \\
\hline Intra team trust $\rightarrow$ Team Effort & $0.714^{* *}$ & 0.514 & 0.0001 \\
Intra team trust $\rightarrow$ Team Monitoring & $0.774^{* *}$ & 0.599 & 0.0000 \\
Team Monitoring $\rightarrow$ Team Effort & $0.724^{* *}$ & 0.529 & 0.0000 \\
\hline ** Correlation is significant at the 0.01 level (2-tailed). & &
\end{tabular}

\section{CONCLUSION AND IMPLICATIONS}

This study aims to examine the relationship between intra team trust and team effort when team monitoring mediates the relationship. The role of intra team trust and team monitoring on team effort is studied in organizations of different sectors in Pakistan. Intra team trust plays an important role in building team effort. The findings of this paper suggest that when trust is built up within a team, the members work better towards the achievement of team and organizational goals. Increased team effort is also built up when the activity of the team members is monitored. Furthermore, in this study, intra team trust is able to explain substantial variance in team effort $\left(R^{2}=0.514\right)$. Team monitoring also shows a substantial variance in team effort $\left(R^{2}=0.529\right)$. Organizations are becoming increasingly competitive and due to globalization and increased competition they are increasing their reliance on teams. Team effort and hence effective attainment of organizational goals can be enhanced when a team members perceives other members to be trustworthy. Intra team trust and team monitoring both create a conducive work environment where members expend greater team effort towards attainment of team and organizational goals. 


\section{REFERENCES}

Angriani, M. R., Ariffin, Z., \& Rahmawati, R. (2017). The influence of psychological climate to the organizational commitment through of job involvement (study at University Foundation Lecturer Achmad Yani (UVAYA) Banjarmasin). International Journal of Business and Economic Affairs, 2(5), 288-296. doi:https://doi.org/10.24088/ijbea-2017-25003

Austin, J. T., \& Vancouver, J. B. (1996). Goal constructs in psychology: Structure, process, and content. Psychological Bulletin, 120(3), 338-375. doi:https://doi.org/10.1037/0033-2909.120.3.338

Axelrod, R., \& Hamilton, W. D. (1981). The evolution of cooperation. Science, 211(4489), 1390-1396.

Baker, D. P., Day, R., \& Salas, E. (2006). Teamwork as an essential component of high-reliability organizations. Health Services Research, 41(4p2), 1576-1598. doi:https://doi.org/10.1111/j.1475-6773.2006.00566.x

Bandura, A. (1997). Self-efficacy: The exercise of control. California, CA: Macmillan: Worth Publishers.

Barber, B. (1983). The logic and limits of trust. London, UK: Sage Publications.

Baron, R. M., \& Kenny, D. A. (1986). The moderator mediator variable distinction in social psychological research: Conceptual, strategic, and statistical considerations. Journal of Personality and Social Psychology, 51(6), 1173-1182. doi:https:// doi.org/10.1037/0022-3514.51.6.1173

Barrick, M. R., Dustin, S. L., Giluk, T. L., Stewart, G. L., Shaffer, J. A., \& Swider, B. W. (2012). Candidate characteristics driving initial impressions during rapport building: Implications for employment interview validity. Journal of Occupational and Organizational Psychology, 85(2), 330-352. doi:https://doi.org/10.1111/j.2044-8325.2011.02036.x

Beaubien, J. M., \& Baker, D. P. (2004). The use of simulation for training teamwork skills in health care: How low can you go? BMJ Quality \& Safety, 13(suppl 1), 51-56. doi:https://doi.org/10.1136/qshc.2004.009845

Bell, B. S., \& Kozlowski, S. W. (2002). A typology of virtual teams: Implications for effective leadership. Group \& Organization Management, 27(1), 14-49. doi:https://doi.org/10.1177/1059601102027001003

Bentler, P. M. (1990). Comparative fit indexes in structural models. Psychological Bulletin, 107(2), 238-246. doi:https:// doi.org/10.1037/0033-2909.107.2.238

Bentler, P. M., \& Bonett, D. G. (1980). Significance tests and goodness of fit in the analysis of covariance structures. Psychological Bulletin, 88(3), 588-590. doi:https://doi.org/10.1037/0033-2909.88.3.588

Browne, M. W., \& Cudeck, R. (1993). Alternative ways of assessing model fit. Testing Structural Equation Models, 154, 136-145. doi:https://doi.org/10.1177/0049124192021002005

Burtscher, M. J., \& Manser, T. (2012). Team mental models and their potential to improve teamwork and safety: A review and implications for future research in healthcare. Safety Science, 50(5), 1344-1354. doi:https://doi.org/10.1016/ j.ssci.2011.12.033

Campion, M. A., Medsker, G. J., \& Higgs, A. C. (1993). Relations between work group characteristics and effectiveness: Implications for designing effective work groups. Personnel Psychology, 46(4), 823-847. doi:https://doi.org/10.1111/ j.1744-6570.1993.tb01571.x

Cannon-Bowers, J. A., \& Salas, E. (1997). Teamwork competencies: The interaction of team member knowledge, skills, and attitudes. In, Workforce readiness: Competencies and assessment. New Jersy, NJ: Erlbaum Hillsdale.

Cannon-Bowers, J. A., Tannenbaum, S. I., Salas, E., \& Volpe, C. E. (1995). Defining competencies and establishing team training requirements. Team Effectiveness and Decision Making in Organizations, 6(7), 333-380.

Carver, C. S., \& Scheier, M. F. (2001). On the self-regulation of behavior. Oxford, UK: Cambridge University Press.

Cascio, W. F. (1995). Whither industrial and organizational psychology in a changing world of work? American Psychologist, 50(11), 928-939. doi:https://doi.org/10.1037/0003-066x.50.11.928

Cohen, S. G., \& Bailey, D. E. (1997). What makes teams work: Group effectiveness research from the shop floor to the executive suite. Journal of Management, 23(3), 239-290. doi:https://doi.org/10.1177/014920639702300303

Conti, B., \& Kleiner, B. H. (1997). How to increase teamwork in organizations. Training for Quality, 5(1), 26-29. doi:https:// doi.org/10.1108/09684879710156496

Cook, J., \& Wall, T. (1980). New work attitude measures of trust, organizational commitment and personal need nonfulfilment. Journal of Occupational Psychology, 53(1), 39-52. doi:https://doi.org/10.1111/j.2044-8325.1980.tb00005 .X

Costa, A. C. (2003). Work team trust and effectiveness. Personnel Review, 32(5), 605-622. 
Damanpour, F., \& Schneider, M. (2006). Phases of the adoption of innovation in organizations: Effects of environment, organization and top managers 1. British journal of Management, 17(3), 215-236. doi:https://doi.org/10.1111/ j.1467-8551.2006.00498.x

De Jong, B. A., \& Elfring, T. (2010). How does trust affect the performance of ongoing teams? The mediating role of reflexivity, monitoring, and effort. Academy of Management Journal, 53(3), 535-549. doi:https://doi.org/10.5465/AMJ.2010 .51468649

De Meuse, K. P., \& Liebowitz, S. J. (1981). An empirical analysis of team-building research. Group \& Organization Studies, 6(3), 357-378. doi:https://doi.org/10.1177/105960118100600311

Denison, D. R., Hart, S. L., \& Kahn, J. A. (1996). From chimneys to cross-functional teams: Developing and validating a diagnostic model. Academy of Management Journal, 39(4), 1005-1023. doi:https://doi.org/10.2307/256721

Devine, D. J., Clayton, L. D., Philips, J. L., Dunford, B. B., \& Melner, S. B. (1999). Teams in organizations: Prevalence, characteristics, and effectiveness. Small Group Research, 30(6), 678-711. doi:https://doi.org/10.1177/104649649903000602

Dickinson, T. L., \& McIntyre, R. M. (1997). A conceptual framework for teamwork measurement. Team Performance Assessment and Measurement, 6(8), 19-43.

Dirks, K. T. (1999). The effects of interpersonal trust on work group performance. Journal of Applied Psychology, 84(3), 445-467. doi:https://doi.org/10.1037/0021-9010.84.3.445

Drucker, P. F. (1992). Organizations. Harvard Business Review, 20(7), 281-293.

Dunphy, D., \& Bryant, B. (1996). Teams: panaceas or prescriptions for improved performance? Human Relations, 49(5), 677-699. doi:https://doi.org/10.1177/001872679604900507

Etzioni, A., Marcus, P., Merton, R. K., Reiss, A., Wilson, J. Q., \& White, H. (1964). Organizations. Englewood Cliffs, NJ: PrenticeHall Publishing.

Ferrin, D. L., Bligh, M. C., \& Kohles, J. C. (2008). It takes two to tango: An interdependence analysis of the spiraling of perceived trustworthiness and cooperation in interpersonal and intergroup relationships. Organizational Behavior and Human Decision Processes, 107(2), 161-178. doi:https://doi.org/10.1016/j.obhdp.2008.02.012

Fornell, C., \& Larcker, D. F. (1981). Structural equation models with unobservable variables and measurement error: Algebra and statistics. Los Angeles, CA: Sage Publications Sage.

Fukuyama, F. (1996). Trust: human nature and the reconstitution of social order. London, UK: Simon and Schuster.

Gann, D. M., \& Salter, A. J. (2000). Innovation in project-based, service-enhanced firms: The construction of complex products and systems. Research Policy, 29(7-8), 955-972. doi:https://doi.org/10.1016/s0048-7333(00)00114-1

Griffin, M. A., Patterson, M. G., \& West, M. A. (2001). Job satisfaction and teamwork: The role of supervisor support. Journal of Organizational Behavior: The International Journal of Industrial, Occupational and Organizational Psychology and Behavior, 22(5), 537-550. doi:https://doi.org/10.1002/job.101

Hackman, J. R. (1990). Groups that work and those that don't. New York, NY: Jossey-Bass.

Hall, P. (2005). Interprofessional teamwork: Professional cultures as barriers. Journal of Interprofessional Care, 19(1), 188-196. doi:https://doi.org/10.1080/13561820500081745

Hinkin, T. R. (1998). A brief tutorial on the development of measures for use in survey questionnaires. Organizational Research Methods, 1(1), 104-121. doi:https://doi.org/10.1177/109442819800100106

Holmbeck, G. N. (1997). Toward terminological, conceptual, and statistical clarity in the study of mediators and moderators: Examples from the child-clinical and pediatric psychology literatures. Journal of Consulting and Clinical Psychology, 65(4), 599. doi:https://doi.org/10.1037/0022-006X.65.4.599

Hoyle, R. H., \& Smith, G. T. (1994). Formulating clinical research hypotheses as structural equation models: A conceptual overview. Journal of Consulting and Clinical Psychology, 62(3), 429-440. doi:https://doi.org/10.1037/0022-006X.62 .3 .429

Jones, G. R., \& George, J. M. (1998). The experience and evolution of trust: Implications for cooperation and teamwork. Academy of Management Review, 23(3), 531-546. doi:https://doi.org/10.5465/amr.1998.926625

Jøsang, A., \& Presti, S. L. (2004). Analysing the relationship between risk and trust. In International Conference on Trust Management, Berlin, Germany.

Kidwell Jr, R. E., \& Bennett, N. (1993). Employee propensity to withhold effort: A conceptual model to intersect three avenues of research. Academy of Management Review, 18(3), 429-456. doi:https://doi.org/10.2307/258904 
Kolbe, M., Grote, G., Waller, M. J., Wacker, J., Grande, B., Burtscher, M. J., \& Spahn, D. R. (2014). Monitoring and talking to the room: Autochthonous coordination patterns in team interaction and performance. Journal of Applied Psychology, 99(6), 1254-1267. doi:https://doi.org/10.1037/a0037877

Kozlowski, S., \& Bell, B. (2003). Work groups and teams in organizations. London, UK: Sage Publications.

Kozlowski, S. W. (1998). Training and developing adaptive teams: Theory, principles, and research. New York, NY: American Psychological Association.

Langfred, C. W. (2004). Too much of a good thing? Negative effects of high trust and individual autonomy in self-managing teams. Academy of Management Journal, 47(3), 385-399. doi:https://doi.org/10.2307/20159588

Lawler, E. E. (1995). Creating high performace organizations: Survey of practices and results of employee involvement and TQM in fortune 1000 companies. New York, NY: Wiley.

LePine, J. A., Piccolo, R. F., Jackson, C. L., Mathieu, J. E., \& Saul, J. R. (2008). A meta-analysis of teamwork processes: Tests of a multidimensional model and relationships with team effectiveness criteria. Personnel Psychology, 61(2), 273-307. doi:https://doi.org/10.1111/j.1744-6570.2008.00114.x

Lewicki, R. J., Bunker, B. B., et al. (1996). Developing and maintaining trust in work relationships. In, Trust in organizations: Frontiers of theory and research. New York, NY: Sage Publications.

Liden, R. C., Wayne, S. J., Jaworski, R. A., \& Bennett, N. (2004). Social loafing: A field investigation. Journal of management, 30(2), 285-304. doi:https://doi.org/10.1016/j.jm.2003.02.002

Luo, X. (2002). Trust production and privacy concerns on the internet: A framework based on relationship marketing and social exchange theory. Industrial Marketing Management, 31(2), 111-118. doi:https://doi.org/10.1016/s0019 -8501(01)00182-1

Manser, T. (2009). Teamwork and patient safety in dynamic domains of healthcare: A review of the literature. Acta Anaesthesiologica Scandinavica, 53(2), 143-151. doi:https://doi.org/10.1111/j.1399-6576.2008.01717.x.

Manz, C. C., \& Sims, H. P. (1995). Business without bosses: How self-managing teams are building high-performing companies. Texas, TX: University of Texas Press.

Marks, M. A., Mathieu, J. E., \& Zaccaro, S. J. (2001). A temporally based framework and taxonomy of team processes. Academy of Management Review, 26(3), 356-376. doi:https://doi.org/10.5465/amr.2001.4845785

Marsh, H. W., \& Hocevar, D. (1985). Application of confirmatory factor analysis to the study of self-concept: First-and higher order factor models and their invariance across groups. Psychological Bulletin, 97(3), 562. doi:https://doi.org/ 10.1037/0033-2909.97.3.562

McAllister, D. J. (1995). Affect-and cognition-based trust as foundations for interpersonal cooperation in organizations. Academy of Management Journal, 38(1), 24-59. doi:https://doi.org/10.2307/256727

McGrath, J. E. (1991). Time, Interaction, and Performance (TIP) a theory of groups. Small Group Research, 22(2), 147-174. doi:https://doi.org/10.1177/1046496491222001

McIntyre, R. M., \& Salas, E. (1995). Measuring and managing for team performance: Emerging principles from complex environments. In, Team Effectiveness and Decision Making in organizations. London, UK: Sage Publications.

Morey, J. C., Simon, R., Jay, G. D., Wears, R. L., Salisbury, M., Dukes, K. A., \& Berns, S. D. (2002). Error reduction and performance improvement in the emergency department through formal teamwork training: Evaluation results of the medteams project. Health Services Research, 37(6), 1553-1581. doi:https://doi.org/10.1111/1475-6773.01104

Mulvey, P. W., \& Klein, H. J. (1998). The impact of perceived loafing and collective efficacy on group goal processes and group performance. Organizational Behavior and Human Decision Processes, 74(1), 62-87. doi:https://doi.org/10.1006/ obhd.1998.2753

Nunnally, J. C., \& Bernstein, I. H. (1994). Psychological theory. New York, NY: MacGraw-Hill.

Phillips, J. M., \& Gully, S. M. (1997). Role of goal orientation, ability, need for achievement, and locus of control in the self-efficacy and goal-setting process. Journal of Applied Psychology, 82(5), 792. doi:https://doi.org/10.1037/0021 $-9010.82 .5 .792$

Putnam, H. (1992). Realism with a human face. London, UK: Harvard University Press.

Rijal, S. (2016). The influence of transformational leadership and organizational culture on learning organization: A comparative analysis of the IT sector, Thailand. Journal of Administrative and Business Studies, 2(3), 121--129. doi:https://doi.org/10.20474/jabs-2.3.3 
Rispens, S., Greer, L. L., \& Jehn, K. A. (2007). It could be worse. International Journal of Conflict Management, 18(3), 325-344. doi:https://doi.org/10.1108/10444060710833450

Robbins, S. P. (2001). Organisational behaviour: Global and southern african perspectives. Cape Town, South Africa: Pearson South Africa.

Rousseau, D. M., Sitkin, S. B., Burt, R. S., \& Camerer, C. (1998). Not so different after all: A cross-discipline view of trust. Academy of Management Review, 23(3), 393-404. doi:https://doi.org/10.5465/amr.1998.926617

Salas, E., Dickinson, T. L., Converse, S. A., \& Tannenbaum, S. I. (1992). Toward an understanding of team performance and training. London, UK: Ablex Publishing.

Salas, E., Sims, D. E., \& Burke, C. S. (2005). Is there a "big five" in teamwork? Small Group Research, 36(5), 555-599. doi:https://doi.org/10.1177/1046496405277134

Saunders, C. S., \& Ahuja, M. K. (2006). Are all distributed teams the same? Differentiating between temporary and ongoing distributed teams. Small Group Research, 37(6), 662-700. doi:https://doi.org/10.1177/1046496406294323

Scardamalia, M., et al. (2002). Collective cognitive responsibility for the advancement of knowledge. Liberal Education in a Knowledge Society, 97, 67-98.

Schippers, M. (2003). Reflexivity in teams. Ridderkerk, Netherlands: Ridderprint.

Stone, P., Kaminka, G. A., Kraus, S., Rosenschein, J. S., et al. (2010). Ad hoc autonomous agent teams: Collaboration without pre-coordination. In Association for the Advancement of Artificial Intelligence, London, UK.

Sundstrom, E., De Meuse, K. P., \& Futrell, D. (1990). Work teams: Applications and effectiveness. American psychologist, 45(2), 120-130.

Sundstrom, E., McIntyre, M., Halfhill, T., \& Richards, H. (2000). Work groups: From the hawthorne studies to work teams of the 1990s and beyond. Group Dynamics: Theory, Research, and Practice, 4(1), 44-67. doi:https://doi.org/10.1037/ 1089-2699.4.1.44

Van Der Vegt, G. S., \& Bunderson, J. S. (2005). Learning and performance in multidisciplinary teams: The importance of collective team identification. Academy of Management Journal, 48(3), 532-547. doi:https://doi.org/10.5465/ AMJ.2005.17407918

VandeWalle, D., Brown, S. P., Cron, W. L., \& Slocum Jr, J. W. (1999). The influence of goal orientation and self-regulation tactics on sales performance: A longitudinal field test. Journal of Applied Psychology, 84(2), 249-259. doi:https://doi.org/ 10.1037/0021-9010.84.2.249

Van Knippenberg, D. (2000). Work motivation and performance: A social identity perspective. Applied Psychology, 49(3), 357-371. doi:https://doi.org/10.1111/1464-0597.00020

Wartika, K., Surendro, H., Satramihardja, I., \& Supriana. (2015). Business process improvement conceptual models to improve the efficiency of power consumption on computer use from the perspective of human resource performance. International Journal of Business and Administrative Studies, 1(3), 99-106. doi:https://doi.org/10.20469/ijbas.10004-3

Way, K. J., Chou, E., \& King, G. L. (2000). Identification of PKC-isoform-specific biological actions using pharmacological approaches. Trends in Pharmacological Sciences, 21(5), 181-187. doi:https://doi.org/10.1016/s0165-6147(00)01468 $-1$

Woodman, R. W., \& Sherwood, J. J. (1980). The role of team development in organizational effectiveness: A critical review. Psychological Bulletin, 88(1), 166-186. doi:https://doi.org/10.1037/0033-2909.88.1.166

Zucker, L. G. (1987). Institutional theories of organization. Annual Review of Sociology, 13(1), 443-464. 